\title{
Colour Sensing Using Robotic ARM
}

\author{
A. Mohamed Nazeer ${ }^{1}$, S. Sasikala ${ }^{2}$, A. Kamalabharathy ${ }^{3}$, S. D. Kirubha Dharshni ${ }^{4}$, M. Nandhini Lakshmi ${ }^{5}$, \\ K. SherinPriya Dharshini ${ }^{6}$ \\ Lecturers, Department of EEE, PSG Polytechnic College, Coimbatore, Tamilnadu , India ${ }^{1,2}$ \\ Students, Department of EEE, PSG Polytechnic College, Coimbatore, Tamilnadu , India ${ }^{3,4,5,6}$
}

\section{Article Info \\ Volume 7, Issue 4 \\ Page Number: 1-10 \\ Publication Issue : \\ July-August-2020}

\section{Article History}

Accepted : 01 July 2020

Published : 07 July 2020

\section{ABSTRACT}

Robots are used in various industries to save the process flow in terms of time and ease. It also improves the process quality of the processed object by reducing the errors. The cost of manufacturing can also be minimized. The proposed system will identify and sort the colour of the yawn in a particular colouring sequence, which is defined in the program. The robot identifies the colour, based on the input given in the keypad. It also picks the object from a source table and place it in a desired destination and vice versa. This Paper aims to select the particular coloured yawn to use it in the machineries. The robot will do pick and place operation by mechanical devices such as gripper and robotic arm. It is carried out on a low cost robot platform for development of pick and place the things. The robot act under the direct control of human or autonomously under the control of the programmed system.

Keywords : Pick and place mechanism, colour sensing, gripping action, manipulation

\section{INTRODUCTION}

Robotics help human kind in almost every industrial field to reduce the human errors and to improve the processing speed. Industries are getting automated to complete necessary tasks at appropriate time without any mistake. This colour sensing robotic arm will increase the speed and productivity in the textile industry by picking the yarns, sorting them by colour and placing it in the desired destination. Colour sensor, Microcontroller (Arduino),wiper and gear motors are included in this system.. The colours are detected by the colour sensor. The colour sensor generates a square wave which is fed to the microcontroller through it's input ports. Microcontroller is used to feed information to the motor drives as programmed. Motor drives are used move the robotic arm to the predefined angle and distance.

\section{PROPOSED SYSTEM}

Colour sorting robotic arm is a system having the ability to select the specified colour object and placing it at a desired location. Firstly, when the object is determined by the robot, the gripper of the robot will pick the object and place it to the specified colour differentiating station. The station consists of a colour 
sensor. Colour sensor mounted on the chip is in the form of a CMOS integrated circuit on the shades RGB colour sensor. The colour sensor consist of the $8^{*} 8$ matrix of photodiodes which totally comprises 64 photodiodes. All these filters collect RGB (red, green, blue) data from the source. The output from the sensor is converted into a square wave. Microcontroller (Arduino), then transfers the signal to the motor drivers to activate the arm to pick the object and drop it to the place defined by programming of controller. The arm rotates to the specific angle in an array arrangement of configurable silicon photodiodes and frequency converter and finally places the object in the desired location.

\section{DIAGRAM:}

The block diagram represents the various blocks of our project. The colour sensor is interfaced with the Arduino board and then the Arduino board is used to drive the motor driver modules L293D and L298. A single L293D IC is capable of running two DC motors at the same time, also the direction of these two motors Wiper motor 1 and Wiper motor 2 can be controlled independently. L298 is used to control the gear motor. The driver modules are used to make a setup which is used to run motors both in clock wise and anti-clockwise direction. Schematically, when the colour sensor board senses the colour of the object yarn it discharges a square wave to the Arduino board which drives up the driver modules according to the colour of the yarn viewed. Accordingly, it drives the motor in the required angles with respect to the colour sensed. The motors used are DC gear motor and Wiper motor. Wiper motor is used for the movement of the arm and the DC gear Motor is used for the gripping action of the object, yarn will be picked and place at the desired destination.

The circuit diagram displays the connection from the arduino board colour sensor to the motors. The analog pins $\mathrm{A} 0, \mathrm{~A} 1, \mathrm{~A} 2$ are connected to the supply. The control pins from the colour system S0,S1,S2,S3 are connected to the digital pins D4,D5,D6,D7.The power supply and ground pins are connected simultaneously with the arduino board.

Further pins D1,D2,D3 are connected with the motors. There are 10 pins in the colour sensor in which two are LED pins used to power the LED. The colour sensor chip (photodiodes) are located centrally in the circuit. The control pins differentiates the colour based on their logic.
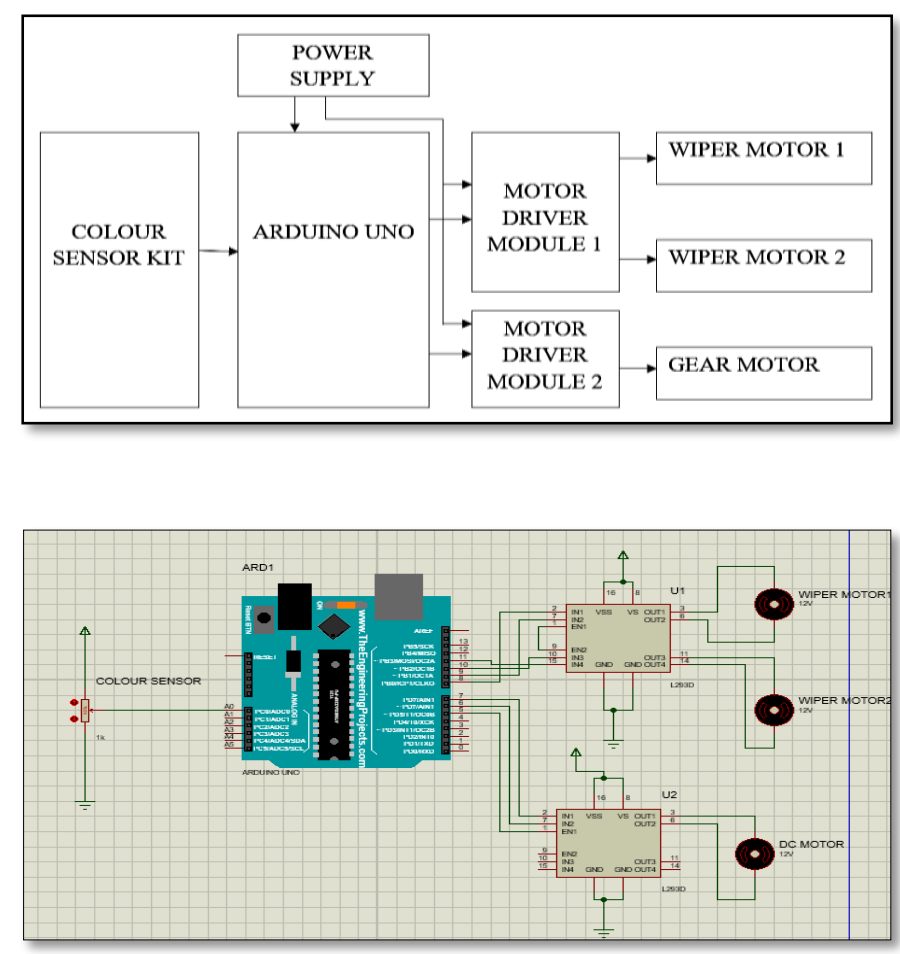

\section{HARDWARE DESCRIPTION}

Colour sorting robotic arm is a system having the ability to select the specified colour object and placing it at a desired location. Firstly, when the object is determined by the robot, the gripper of the robot will pick the object and place it to the specified colour differentiating station. The station consist of a colour sensor. Colour sensor mounted on the chip is in the form of a CMOS integrated circuit on the shades RGB 
colour sensor. Colour sensor consist of $8^{*} 8$ matrix of photodiodes totally 64 filter sensors are used in it. All these filters collect RGB (red, green, blue) data from the source. The output from the sensor is converted into a square wave. Microcontroller then transfers the signal to the motor drivers to activate the arm to pick the object and drop it to the place defined by programming of controller. The arm rotates to the specific angle (may be 90) in an array arrangement of configurable silicon photodiodes and frequency converter and finally places the object in the desired location. Pick and place robot speeds up the process involved in the colour segregation. It also increases the productivity by saving the time of the people in picking the thread and placing it in the proper boxes.

The main unit has Microcontroller (Arduino), Wiper motors, Gear motor and other components. Voltage regulator is used to provide the power supply for the circuit board. Pin no. 1 is connected with the pull up resistor of $1 \mathrm{kohm}$ and the capacitor of 0.1 microfarad capacitor. The pins 11 and 32 are connected to positive potential and pin 12 and 31 are connected to the negative potential. The wiper motors are used to control the arm of the robot. Each motor gets controlled by the motor driver module. The input of the driver is connected to the input pin, mode and direction selection. Gear motor is used for gripping action.

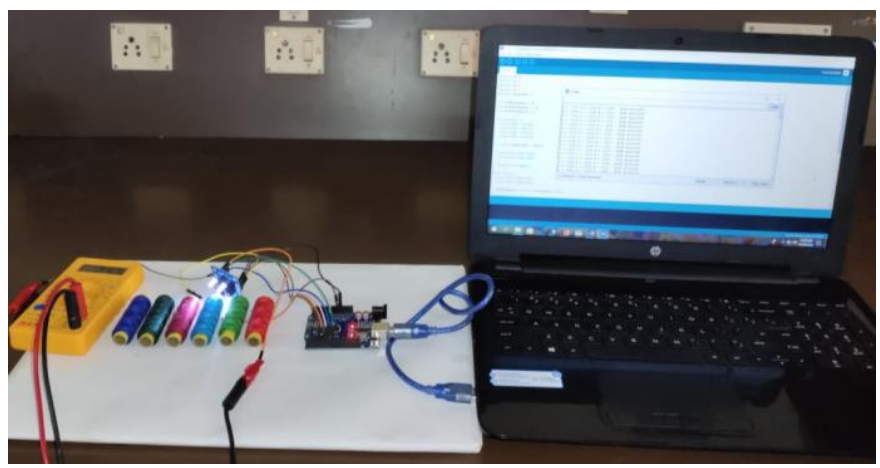

\section{SOFTWARE DESCRIPTION}

The software used to program the microcontroller is Arduino Integrated Development Environment. It is written in java, has more built-in libraries and objects. It is provided by the arduino manufacturer. It has built in tools to verify sensor inputs, and outputs. It is released under LGPL or GPL licence. Arduino IDE can be used for all boards manufactured by arduino.

\section{RED}

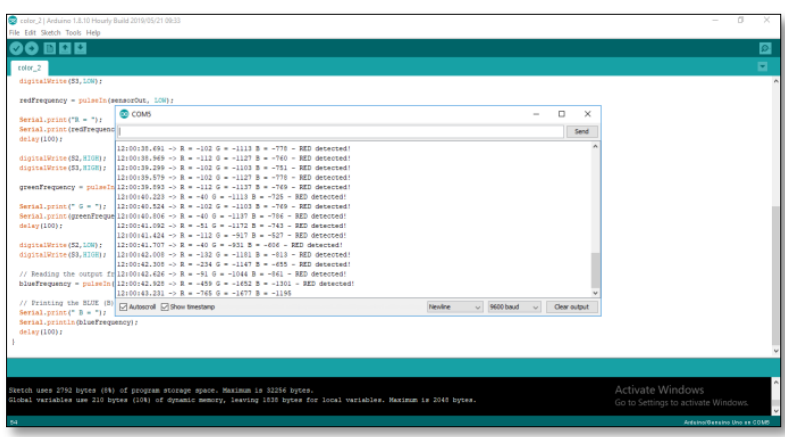

$\mathrm{R}=408 \mathrm{G}=182 \mathrm{~B}=316-\mathrm{RED}$ detected!

$R=397 \mathrm{G}=182 \mathrm{~B}=320-$ RED detected!

$R=428 \mathrm{G}=216 \mathrm{~B}=320-\mathrm{RED}$ detected!

\section{GREEN}

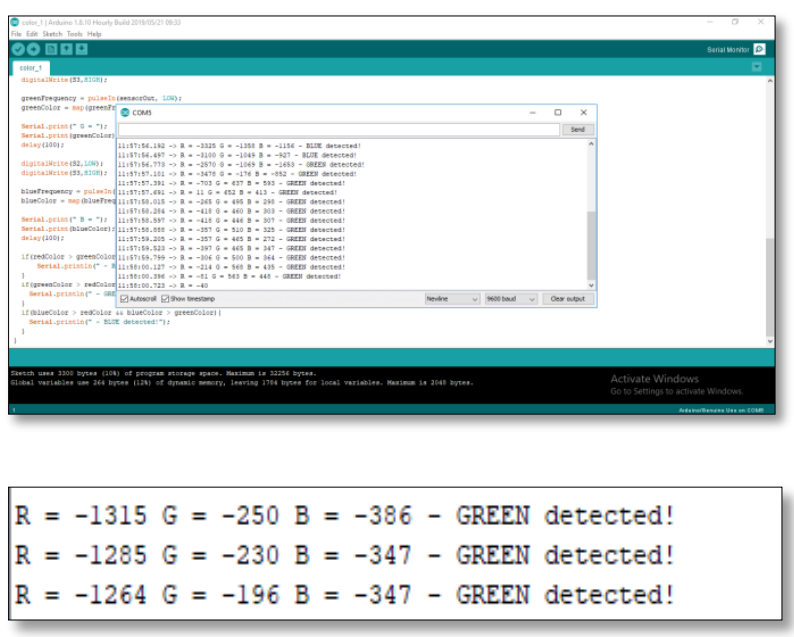




\section{BLUE}

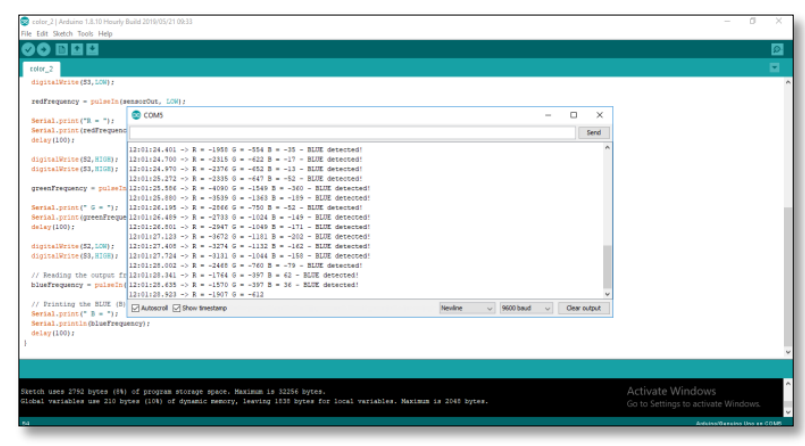

$R=-173 G=598 B=677-$ BLUE detected!

$R=-173 G=563 B=646-$ BLUE detected!

$R=-183 G=598 B=677-$ BLUE detected!
The above pictures shows the frequency ranges and their corresponding output colours. The frequency range of red colour is between 397 to 428 for corresponding colours red, pink and orange all comes under the red colour family. The frequency range of green colour is between 196 to 250 for corresponding colours lime green, olive green and dark green which all comes under the green colour family. The frequency range of blue colour is between 346 to 677 for corresponding colours light blue, dark blue and deep blue which all comes under the blue colour family.

\section{RESULT}

\begin{tabular}{|c|c|c|c|c|}
\hline S.NO & $\begin{array}{c}\text { COLOUR OF THE } \\
\text { OBJECT }\end{array}$ & $\begin{array}{c}\text { COLOUR SENSOR } \\
\text { OUPUT }\end{array}$ & $\begin{array}{c}\text { OUTPUT FREQUENCY } \\
(\mathrm{Hz})\end{array}$ & $\begin{array}{c}\text { OUTPUT VOLTAGE } \\
(\mathrm{V})\end{array}$ \\
\hline 1. & Red & Red & 408 & 2.68 \\
\hline 2. & Pink & Red & 397 & 2.48 \\
\hline 3. & Orange & Red & 428 & 2.8 \\
\hline 4. & Lime Green & Green & 250 & 2.48 \\
\hline 5. & Dark Green & Green & 230 & 2.2 \\
\hline 6. & Olive Green & Green & 196 & 2.72 \\
\hline 7. & Light Blue & Blue & 646 & 2.45 \\
\hline 8. & Dark Blue & Blue & 677 & \\
\hline 9. & Deep Blue & Blue & 677 & \\
\hline
\end{tabular}

RED :

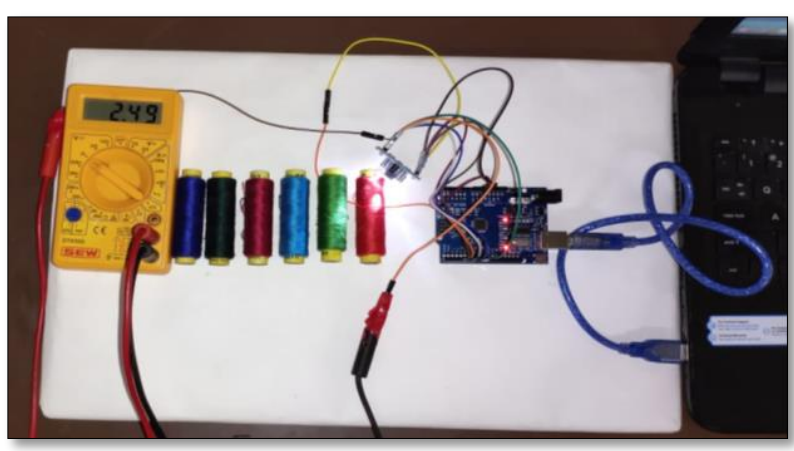

GREEN :

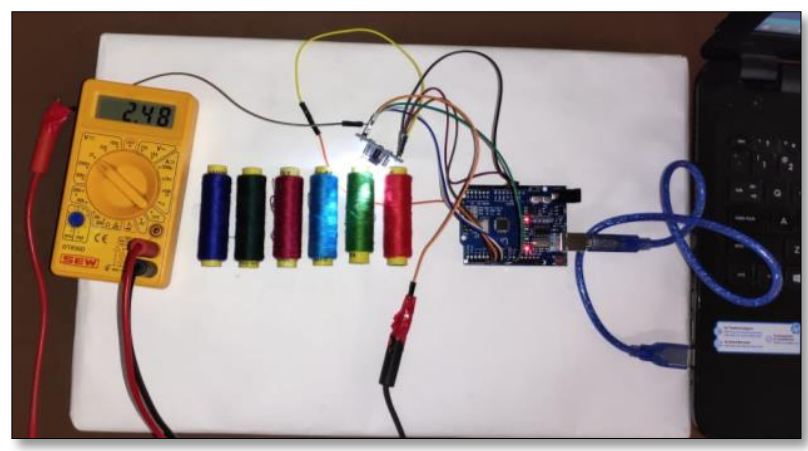




\section{BLUE:}
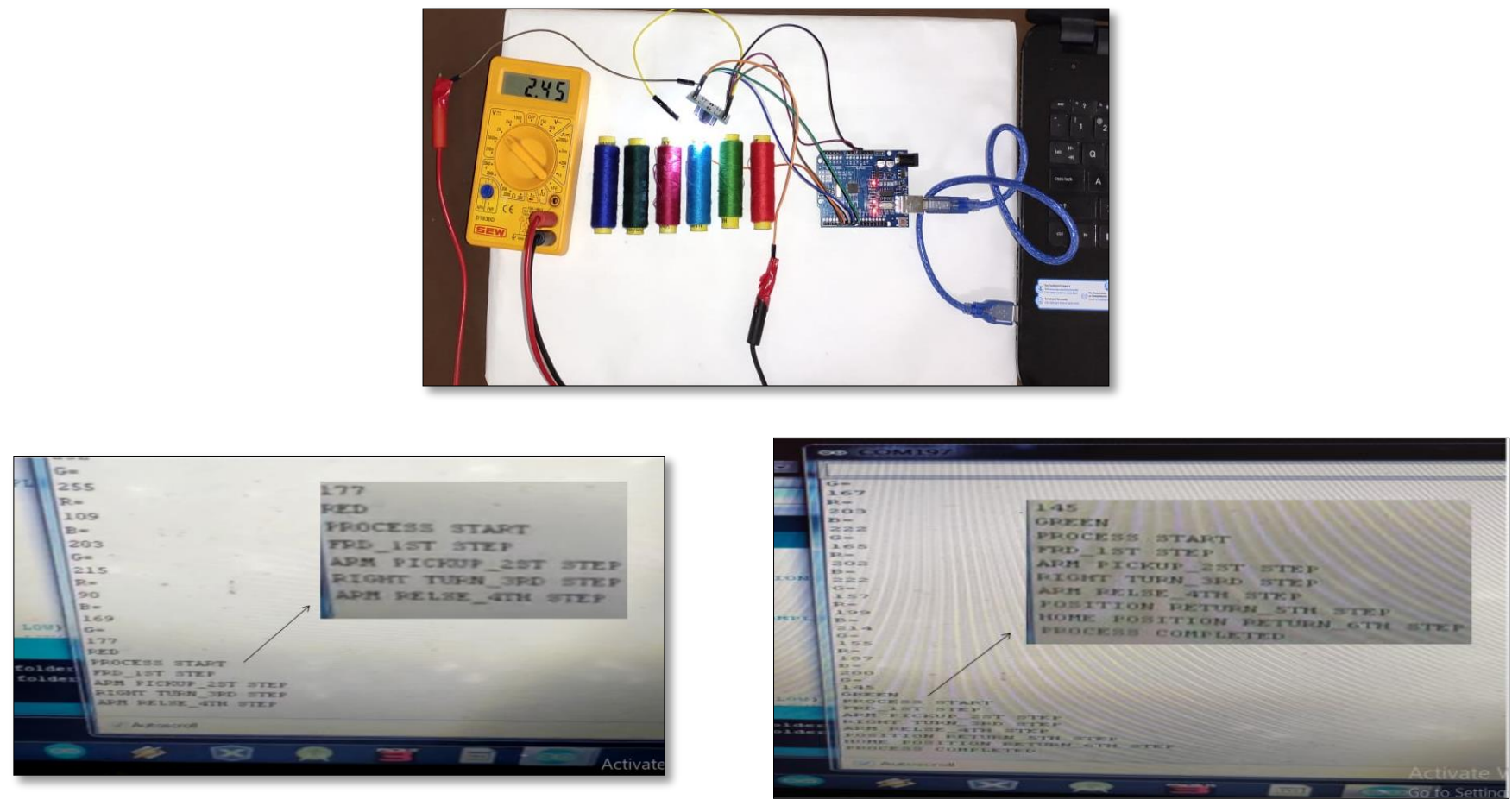

Colour Detection
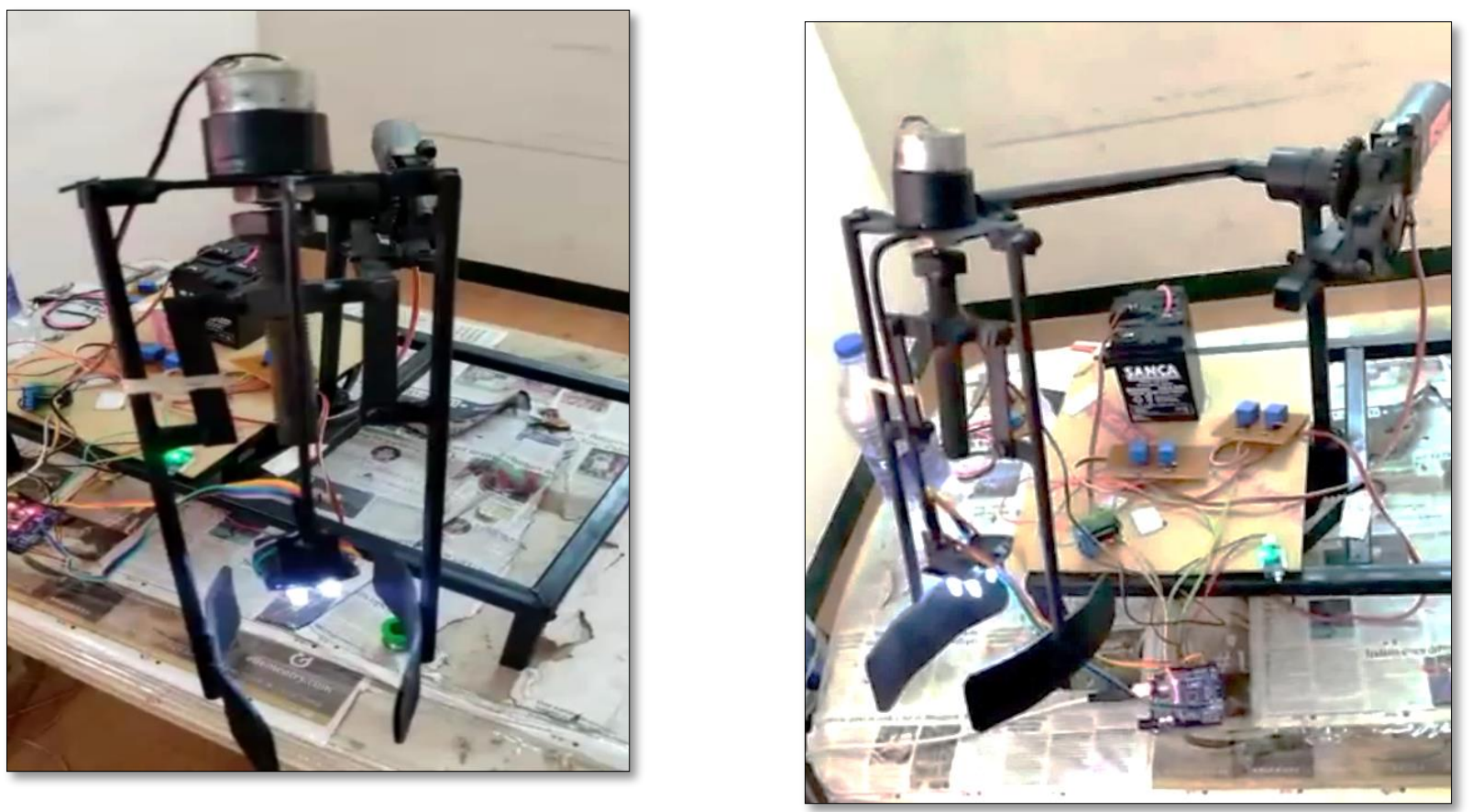

Movement of the Robotic arm 


\section{IV.CONCLUSION}

The system has been successfully designed and it has the ability to perform the required task. The colour sensor performs two main tasks, object detection and colour recognition. This is a cost effective system and designed to perform continuous and reliable task without any human errors. The proposed robotic system are useful in industries, since this system is controlled by the microcontroller, the result obtained are reliable and faster. This system also reduces the involvement of the mankind.

\section{REFERENCES}

[1]. Dhanoj M, Reshma K V, Sheeba V, Marymol P Assistant Professor, E\&I Department, VJEC, Chemperi Kerala, India1,2,3,4 "Color Sensor Based Objects Sorting Robot Using Embedded System"

[2]. Ahmed M. A, Haidar1, Chellali, Benachaiba, Mohamad, Zahir, "Software Interfacing of Servo Motor with Microcontroller", Journal of Electrical Systems,

[3]. Balkeshwar Singh, Kumaradhas, N. Sellappan, "Evolution of Industrial Robots and their Applications", IJEIT, Volume 2, Issue 2, November 2011 .

\section{Cite this article as :}

A. Mohamed Nazeer, S. Sasikala, A. Kamalabharathy, S. D. Kirubha Dharshni, M. Nandhini Lakshmi, K. SherinPriya Dharshini, "Colour Sensing Using Robotic ARM", International Journal of Scientific Research in Science and Technology (IJSRST), Online ISSN : 2395-602X, Print ISSN : 2395-6011, Volume 7 Issue 4, pp. 104-109, July-August 2020. Available at doi : https://doi.org/10.32628/IJSRST207430 Journal URL : http://ijsrst.com/IJSRST207430 